\title{
Coexpression of the IGF-IR, EGFR and HER-2 is common in colorectal cancer patients
}

\author{
MATTHEW P. CUNNINGHAM ${ }^{1}$, SHARADAH ESSAPEN ${ }^{2}$, HILARY THOMAS $^{1,2}$, MARGARET GREEN $^{3}$, \\ DAVID P. LOVELL ${ }^{1}$, CLARE TOPHAM $^{2}$, CHRISTOPHER MARKS $^{4}$ and HELMOUT MODJTAHEDI ${ }^{1}$ \\ ${ }^{1}$ Division of Oncology, Postgraduate Medical School, Guildford, Surrey GU2 7WG; ${ }^{2}$ St. Luke's Cancer Centre, \\ ${ }^{3}$ Department of Histopathology, ${ }^{4}$ Colorectal Unit, Royal Surrey County Hospital, Guildford, Surrey GU2 5XX, UK
}

Received August 31, 2005; Accepted October 4, 2005

\begin{abstract}
Signalling via the insulin-like growth factor-I receptor (IGF-IR) has been associated with resistance to antiepidermal growth factor receptor (EGFR) and human epidermal growth factor receptor-2 (HER-2)-based therapies in the experimental system, but the coexpression and clinical significance of the IGF-IR, EGFR and HER-2 in cancer patients remains unclear. IGF-IR, EGFR, and HER-2 status was assessed retrospectively in tumour specimens from 87 Dukes' C colorectal cancer patients using immunohistochemistry. Sections were scored by the percentage of positive cells (membrane and cytoplasmic) and intensity of staining. The association between receptor coexpression and clinicopathological parameters and overall survival were evaluated using univariate and multivariate (Cox) analysis. Overall, 93, 83 and $89 \%$ of the cases expressed IGF-IR, EGFR and HER-2, respectively. While $60 \%$ of the cases expressed membranous IGF-IR, the expression of EGFR and HER-2 was predominantly cytoplasmic. Coexpression of the IGF-IR, EGFR and HER-2 was present in tumours from $75 \%$ of the patients. No significant association was found between the expression or coexpression of total IGF-IR, EGFR and HER-2 and clinicopathological parameters or overall survival. Our results indicate that coexpression of IGF-IR, EGFR and HER-2 is common in Dukes' C colorectal cancer, warranting further investigation on the co-targeting of such receptors in colorectal cancer patients.
\end{abstract}

\section{Introduction}

Colorectal cancer is one of the major causes of cancer death in the world (1). The majority of colorectal cancer patients are diagnosed with locally advanced or metastatic disease and

Correspondence to: Dr Helmout Modjtahedi, Division of Oncology, Postgraduate Medical School, Manor Park, University of Surrey, Guildford, Surrey GU2 7WG, UK

E-mail: h.modjtahedi@surrey.ac.uk

Key words: growth factor receptors, colorectal cancer, Dukes' C, prognosis, therapy have a poor response to conventional forms of therapy. The identification of more specific therapeutic targets and molecular marker(s) that aid the early detection of cancer, predict cancer prognosis and the response to therapy can help to reduce mortality from colorectal cancer (2).

The results of several studies in the experimental system suggest that the insulin-like growth factor I receptor (IGF-IR) system has mitogenic and antiapoptotic properties and may therefore play an important role in the pathophysiology of human cancers. The IGF-IR is a growth factor receptor with tyrosine kinase activity. The binding of ligand (IGF-I, IGF-II) to IGF-IR ultimately leads to the activation of multiple downstream signalling cascades involved in cell proliferation and promoting cell survival. Dysregulation of signalling via the IGF-IR and/or its ligands has been associated with the establishment and maintenance of the transformed phenotype, angiogenesis, invasion, metastases, and resistance to apoptosis, conventional and receptor-specific forms of therapy (3-6). In addition, IGF-IR inhibition with receptor-specific blocking monoclonal antibodies (mAbs), small molecule tyrosine kinase inhibitors (TKIs), antagonistic peptides or anti-sense oligonucleotides has been shown to inhibit growth of a wide range of IGF-IR-expressing tumour cells (e.g. breast, lung, multiple myeloma) both in vitro and in vivo, and to increase the response to conventional forms of therapy $(3,6,8,9)$. Further studies in the experimental system have demonstrated that the IGF-IR can transactivate other growth factor receptor families (e.g. EGFR) to enhance the malignant behaviour of tumour cells, and the continuous activation of the IGF-IR pathway has also been implicated as one of the factors responsible for the development of tumour cells resistant to therapy with the anti-HER-2 mAb trastuzumab and EGFR inhibitors (7,10-13). More recently, the combination of IGF-IR targeted therapy with anti-EGFR or anti-HER-2 therapeutic strategies has been shown to enhance the anti-tumour activity of such agents $(14,15)$.

The expression of IGF-IR (at mRNA or protein level) has been reported in the tumours from a number of different tissues including colorectal cancer (16-22). While some studies have reported no difference in IGF-IR expression between malignant and normal colorectal tissues $(17,22)$, other studies have found a significantly higher level of IGF-IR in malignant colorectal tissues but no clear association with clinicopathological parameters or prognosis (18-20). These studies therefore 
provide a rationale for investigating the coexpression of the IGF-IR, EGFR and HER-2 in human malignancies, and their association with clinicopathological parameters, patient survival and response to therapy.

We have shown previously that overexpression of the HER-2 is common in patients with Dukes' B and C colorectal cancer (23). In this study, we therefore determined the coexpression of IGF-IR, EGFR and HER-2 in tumour specimens from Dukes' C (node positive) colorectal cancer patients using immunohistochemistry. We also investigated the association between the coexpression of IGF-IR, EGFR and HER-2 and clinicopathological parameters and overall survival.

\section{Materials and methods}

Patient information. Eighty-seven patients with Dukes' C colorectal cancer were included in this retrospective study. This group consisted of consecutive patients who underwent radical surgery at the Royal Surrey County Hospital (Guildford, UK) between January 1990 and December 1998, excluding those with no follow-up information, mis-diagnosis, and incomplete histology. Cases of peri- and post-operative death (i.e. within 30 days after surgery) were excluded from this study, as were those with positive tumour resection margins on microscopy, and those with tumour blocks in a condition too poor for immunohistochemical use. Ethical approval was obtained from the Research and Development Committee of the Royal Surrey County Hospital. Detailed clinicopathological information, including patient age and gender as well as tumour size, was available for each patient.

Tumour cell lines and antibodies. The human breast (MCF-7 and SKBR3) and head and neck carcinoma (HN5) cell pellets were used as positive controls for IGF-IR, HER-2 and EGFR staining, respectively. The IGF-IR negative R- cell line was a kind gift from Dr Renato Baserga (Kimmel Cancer Institute, Philadelphia, PA) and was used as a negative control for IGF-IR staining (11). All cell lines were cultured routinely in Dulbecco's modified Eagle's medium supplemented with $10 \%$ FCS and the antibiotics penicillin, streptomycin, and neomycin. For R- cells, the medium also contained $50 \mu \mathrm{g} / \mathrm{ml}$ of hygromycin $\mathrm{B}$.

The expression of IGF-IR in the tumour specimens was determined using a mouse monoclonal antibody (mAb) directed against the $\alpha$-subunit (extracellular domain) of the human IGF-IR (Calbiochem). The expression of EGFR and HER-2 was determined using the rat mAbs ICR16 and ICR12 which are directed against the external domain of the human EGFR and HER-2, respectively $(24,25)$.

Immunohistochemistry. Paraffin-embedded sections of tumour specimens $(3 \mu \mathrm{m})$ and control cell pellets were cut from paraffin-embedded blocks. Sections were de-waxed in xylene, washed three times in industrial methylated spirit, and rehydrated to water, as described previously (23). Following deparaffinisation and rehydration, sections were washed in Tris-buffered saline (TBS) for $5 \mathrm{~min}$, and unmasked in citrate antigen unmasking solution (Vector laboratories, Peterborough, $\mathrm{UK}$ ), in a pressure cooker at operating temperature for $1 \mathrm{~min}$.
Slides were then immersed in tap water and washed in TBS for $5 \mathrm{~min}$, prior to the blockade of endogenous peroxidase and biotin (Zymed) and incubation with rabbit serum for $20 \mathrm{~min}$. Each section was incubated for $1 \mathrm{~h}$ at room temperature with mouse anti-human IGF-IR antibody (1/50 in TBS). The bound primary antibody was then detected by addition of biotinylated rabbit anti-mouse secondary antibody (Dako, CA, USA) followed by avidin/biotin/horseradish peroxidase complex (Dako) for $30 \mathrm{~min}$ each at room temperature. The immunostaining was then visualised using liquid diaminobenzidine diluted 1/50 in HRP substrate buffer (Dako), and sections were counterstained with Mayer's haematoxylin before mounting.

No antigen retrieval was necessary in the staining of tumour sections with anti-EGFR mAb ICR16 and anti-HER-2 $\mathrm{mAb}$ ICR12. Following deparaffinisation and rehydration, sections were washed in TBS for $5 \mathrm{~min}$, prior to the blockade of endogenous peroxidase and incubation with rabbit serum for $20 \mathrm{~min}$. After blotting off excess serum, each section was incubated with $200 \mu 1$ of hybridoma culture supernatant (diluted $1 / 4$ in TBS for ICR 12 and $1 / 2$ for ICR16) overnight at $4{ }^{\circ} \mathrm{C}$. The bound primary antibody was then detected by addition of biotinylated rabbit anti-rat secondary antibody (Dako) for $30 \mathrm{~min}$ at room temperature (1/300 in TBS). Finally, the visualisation, counterstaining and mounting of the sections were performed as described above.

Sections were scored by the percentage of positive cells (membranous and cytoplasmic) and the intensity of immunostaining [i.e. negative (0), weak (1+), intermediate (2+), and strong (3+)]. Immunostaining in $>10 \%$ of tumour cells was considered positive. The immunostaining was scored by two independent observers without prior knowledge of clinicopathological parameters. Any disparity in scoring was resolved by simultaneous reassessment by both observers.

Statistical analysis. The association between immunohistochemistry scores and patient clinicopathological data was assessed using the Chi-Squared test (Pearson Chi-Square). Univariate analysis of survival was performed using KaplanMeier survival plots, and evaluation of differences between groups was performed with the log rank-test. For multivariate analysis, the Cox proportional hazards regression model was used to detect the impact of patient clinicopathological parameters and receptor expression on overall survival. Using a stepwise forward selection method, the covariates considered for inclusion in the model were site and size of tumour, depth of tumour invasion (i.e. T stage), grade, lymphovascular invasion, node stage, (N1 or N2), and the presence of apical node metastases. Patient treatment with chemotherapy or radiotherapy was also included in the model. Significance levels were set at $\mathrm{P}<0.05$, and all statistical analyses were carried out using the Statistical Package for the Social Sciences (SPSS) versions 11.5.1 and version 12.0 for Windows (SPSS UK Ltd., Woking, Surrey, UK).

\section{Results}

Clinicopathological features. Patient clinicopathological characteristics are detailed in Table I. All 87 patients were diagnosed with node positive (Dukes' C, N1/N2) colorectal 
Table I. Association between clinicopathological parameters and overall survival using Kaplan-Meier survival curves and the log-rank test, and between clinicopathological parameters and expression of IGF-IR, HER-2 or EGFR, and coexpression of IGF-IR, HER-2 and EGFR determined using the chi-squared test.

\begin{tabular}{|c|c|c|c|c|c|c|c|c|c|}
\hline \multirow[t]{2}{*}{ Characteristic (n) } & \multirow{2}{*}{$\begin{array}{c}\text { P-value for } \\
\text { overall } \\
\text { survival }\end{array}$} & \multicolumn{8}{|c|}{$\begin{array}{l}\text { Number of patients with }>10 \% \text { receptor expression } \\
\text { (P-value for association with patient characteristics) }\end{array}$} \\
\hline & & \multicolumn{2}{|c|}{ IGF-IR } & \multicolumn{2}{|c|}{ HER-2 } & \multicolumn{2}{|c|}{ EGFR } & \multicolumn{2}{|c|}{ All three } \\
\hline \multicolumn{10}{|l|}{ Sex } \\
\hline Male (47) & & 43 & & 40 & & 36 & & 31 & \\
\hline Female (40) & NS & 38 & NS & 37 & NS & 36 & NS & 34 & NS \\
\hline \multicolumn{10}{|l|}{ Age in year } \\
\hline$\leq 70(47)$ & & 43 & & 42 & & 41 & & 37 & \\
\hline$>70(40)$ & 0.014 & 38 & NS & 35 & NS & 31 & NS & 28 & NS \\
\hline \multicolumn{10}{|l|}{ Tumour site } \\
\hline Right colon (26) & & 23 & & 23 & & 20 & & 17 & \\
\hline Left colon (24) & & 24 & & 20 & & 21 & & 20 & \\
\hline Rectum (37) & NS & 24 & NS & 34 & NS & 31 & NS & 28 & NS \\
\hline \multicolumn{10}{|l|}{ Size } \\
\hline$\leq 5 \mathrm{~cm}(56)$ & & 53 & & 50 & & 45 & & 41 & \\
\hline$>5 \mathrm{~cm}(31)$ & NS & 28 & NS & 27 & NS & 27 & NS & 24 & NS \\
\hline \multicolumn{10}{|l|}{ Grade } \\
\hline $1(3)$ & & 3 & & 2 & & 3 & & 2 & \\
\hline $2(48)$ & & 46 & & 42 & & 39 & & 37 & \\
\hline $3(32)$ & & 29 & & 30 & & 27 & & 24 & \\
\hline Mucinous (4) & NS & 3 & NS & 3 & NS & 3 & NS & 2 & NS \\
\hline \multicolumn{10}{|l|}{$\begin{array}{l}\text { Lymphovascular } \\
\text { invasion }\end{array}$} \\
\hline Absent (65) & & 60 & & 56 & & 54 & & 48 & \\
\hline Present (22) & NS & 21 & NS & 21 & NS & 18 & NS & 17 & NS \\
\hline \multicolumn{10}{|l|}{ T stage } \\
\hline T2 (10) & & 9 & & 9 & & 9 & & 8 & \\
\hline T3 (56) & & 54 & & 49 & & 48 & & 44 & \\
\hline $\mathrm{T} 4(21)$ & 0.0012 & 18 & NS & 19 & NS & 15 & NS & 13 & NS \\
\hline \multicolumn{10}{|l|}{ Apical node } \\
\hline Negative (45) & & 43 & & 40 & & 38 & & 35 & \\
\hline Positive (11) & & 11 & & 11 & & 10 & & 10 & \\
\hline Unknown (31) & 0.0068 & 27 & NS & 26 & NS & 24 & NS & 20 & NS \\
\hline \multicolumn{10}{|l|}{ Positive nodes } \\
\hline 1-3 nodes (57) & & 51 & & 49 & & 47 & & 40 & \\
\hline $4+$ nodes $(30)$ & NS & 30 & NS & 28 & NS & 25 & NS & 25 & NS \\
\hline
\end{tabular}

NS, not significant $(\mathrm{P}>0.05)$.

cancer. The median patient follow-up time was 4.1 years. Fifty patients had a cancer of the colon (including 6 rectosigmoid cancers) and 37 patients had a cancer of the rectum. Twenty-six patients received post-operative radiotherapy, and of these, 20 had a cancer of the rectum and 6 had a rectosigmoid cancer. Forty-nine patients received post-operative chemotherapy. None of the patients had received radiotherapy or chemotherapy before surgery. There was a poorer survival in patients with $\mathrm{T}$ stage 4 disease $(\mathrm{P}=0.001)$, those with apical node metastases $(\mathrm{P}=0.007)$, and in patients $>70$ years old $(\mathrm{P}=0.014)$. No significant association was found between survival and the other factors (Table I). 

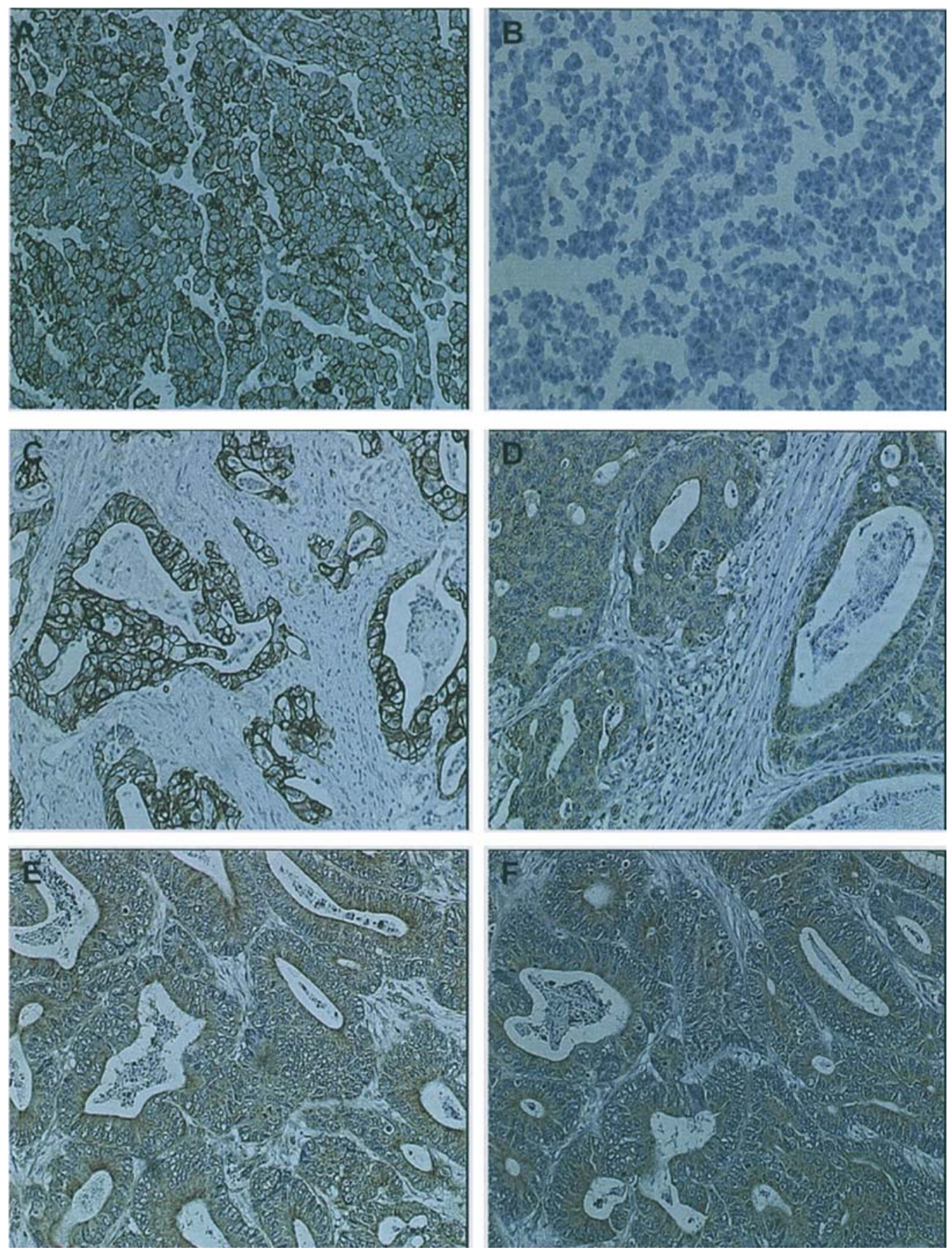

Figure 1. Immunohistochemical staining of the IGF-IR positive MCF-7 cell pellet (A), and the IGF-IR negative R- cell pellet (B). Predominantly membranous (C) and cytoplasmic (D) IGF-IR staining of two different colorectal cancer cases. Predominantly cytoplasmic 3+ HER-2 staining (E) and cytoplasmic 2+ EGFR staining $(\mathrm{F})$ in a selected colorectal cancer case.

The expression of IGF-IR, EGFR and HER-2 in colorectal tumours. The anti-IGF-IR antibody used in this study is specific for the IGF-IR (Fig. 1). This antibody stained the membrane of the IGF-IR expressing cell line MCF-7 with strong intensity, but did not stain the cell pellet of the nonIGF-IR expressing cell line R- (Fig. 1A and B). IGF-IR expression was found to be positive in 81 (93\%) of 87 Dukes' C colorectal cancer cases (Table II). The pattern of IGF-IR immunostaining was both membranous and cytoplasmic (Fig. 1C and D). Where membrane IGF-IR was present, the intensity of staining was of abundantly strong (3+) intensity
(Fig. 1C). Membranous IGF-IR was present in $52(60 \%)$ of the cases (Table II).

Of 87 cases examined, 77 (89\%) and $72(83 \%)$ were HER-2 or EGFR positive, respectively (Table II; Fig. 1E and F) Unlike staining of the IGF-IR, membrane expression of HER-2 and EGFR was typically confined to a low percentage of cases and tumour cells (Table II). The intensity of HER-2 and EGFR immunostaining was similar with respect to the number of cases with $1+$ and $2+$ immunostaining; however, there were more cases with $3+$ intensity immunostaining for HER-2 than for EGFR (Table II). Staining for EGFR and 
A

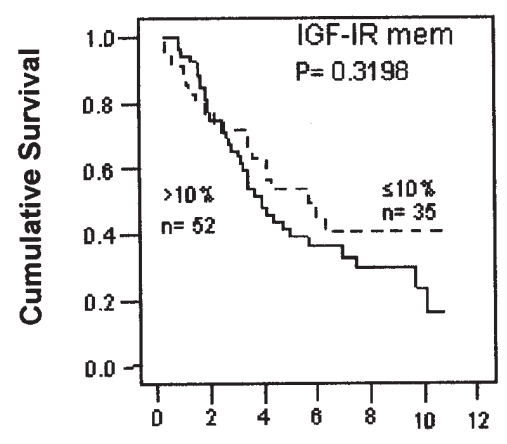

Overall Survival (Years)

C

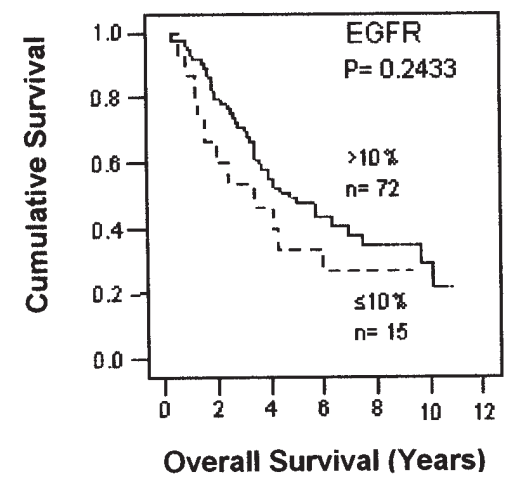

B

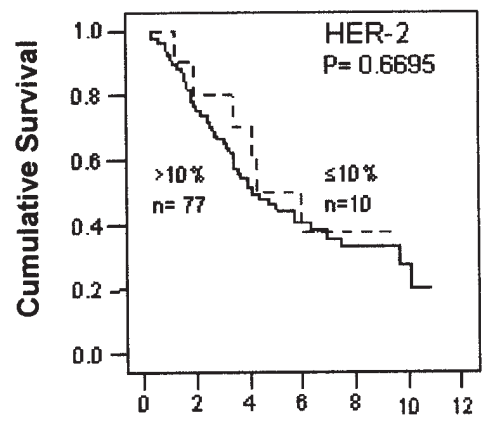

Overall Survival (Years)

D

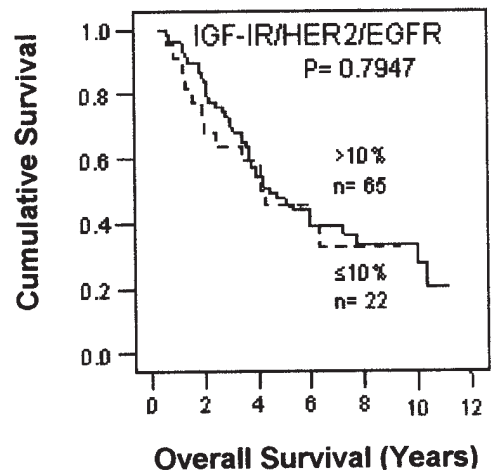

Figure 2. Kaplan Meier survival curves for Dukes' C colorectal cancer patients expressing >10\% IGF-IR, EGFR, and HER-2. Overall survival in patients expressing membranous IGF-IR (A), total HER-2 (B), total EGFR (C), and patients with IGF-IR, EGFR and HER-2 coexpression (D).

HER-2 was noticeable in structurally benign glands and also the stroma of colorectal cancer tissues, whereas IGF-IR was not expressed in the stroma of any biopsies.

The association between IGF-IR, EGFR and HER-2 expression and clinicopathological parameters and overall survival. The expression of IGF-IR, EGFR and HER-2 was evaluated with respect to clinicopathological features (Table I) and overall survival (Fig. 2). No associations were found between total IGF-IR expression (membranous and cytoplasmic) and clinicopathological parameters or overall survival (Table I, data not shown). However, significant associations were found between the expression of membranous IGF-IR in $>10 \%$ of tumour cells and tumour size, with more expression in tumours $\leq 5 \mathrm{~cm}$ $(\mathrm{P}=0.001)$, patient age, with more expression in patients $>70$ years $(\mathrm{P}=0.025)$ (data not shown), but not overall survival (Fig. 2A). Similarly to total IGF-IR expression, there were no significant associations between HER-2 expression, EGFR expression, and the coexpression of the IGF-IR, HER-2 and EGFR and clinicopathological parameters (Table I) or overall survival (Fig. 2B-D).

\section{Discussion}

In recent years, aberrant expression of growth factor receptors (e.g. EGFR, HER-2, IGF-IR) has been reported in many cancer cell lines and tissues, associated with the establishment and maintenance of the transformed phenotype, and in some cases has been associated with a poor prognosis and resistance to therapy $(3,4,26,27)$. In addition, the results of other experimental studies have indicated that the IGF-IR can interact with EGFR and HER-2 to enhance the malignant behaviour of tumours, and that IGF-IR signalling may be responsible for the poor response to therapy with EGFRspecific inhibitors or the anti-HER-2 mAb tratsuzumab $(10,12-15)$. Consequently, in this study we investigated the coexpression of IGF-IR, EGFR and HER-2 in Dukes' C colorectal cancer specimens and determined their association with clinicopathological parameters and overall survival.

We have found that a high percentage $(93 \%)$ of Dukes' C (node positive) colorectal cancer patients are IGF-IR positive (Table I and II). The expression of IGF-IR has been reported previously in both normal and malignant tissues from a wide range of cancer patients including colorectal cancer (16-22). The great majority of studies have found no significant difference in the levels of IGF-IR mRNA between normal and malignant colorectal tissues $(17,22)$. However, like other immunohistochemical studies, we found that IGF-IR overexpression is common in tumour specimens from colorectal cancer patients (18-20) but the expression of IGF-IR is not associated with clinicopathological parameters (Table I) $(19,20,22)$. When our data was analysed using patients with $>10 \%$ membranous IGF-IR expression, $60 \%$ of the cases were IGF-IR positive (Table II) and there were significant 
Table II. Distribution of IGF-IR, HER-2 and EGFR protein expression in colorectal cancer $(n=87)$, using the anti-humanIGF-IR mAb, mAb ICR16, or mAb ICR12.

\begin{tabular}{llllr}
\hline $\begin{array}{l}\text { Percentage } \\
\text { of positive } \\
\text { tumour cells }\end{array}$ & \multicolumn{4}{l}{$\begin{array}{l}\text { Number of cases with receptor expression } \\
\text { [cytoplasmic }+ \text { membrane (membrane only)] }\end{array}$} \\
\cline { 2 - 5 } & IGF-IR & HER-2 & EGFR \\
\hline Negative & $6(35)$ & $10(82)$ & $15(86)$ \\
$>10$ & $81(52)$ & $77(5)$ & $72(1)$ \\
$>50$ & $62(12)$ & $66(0)$ & $55(0)$ \\
\hline Antibody to: & \multicolumn{5}{c}{ Overall intensity of staining } \\
\cline { 2 - 5 } & 0 & $1+$ & $2+$ & $3+$ \\
\cline { 2 - 5 } IGF-IR & 4 & 41 & 35 & 7 \\
HER-2 & 6 & 43 & 16 & 22 \\
EGFR & 11 & 51 & 17 & 8 \\
\hline
\end{tabular}

${ }^{\text {a }}$ Data are shown according to the percentage of reactive cells and overall intensity of staining. 0 , negative; $1+$, weak staining; $2+$, moderate staining, $3+$, strong staining.

associations with tumour size $(\mathrm{P}=0.001)$, with higher expression in tumours $<5 \mathrm{~cm}$. The limited number of studies investigating the association between IGF-IR and clinicopathological parameters, the use of different cut-off values for IGF-IR positive tumours, together with the use of different primary antibodies, heterogeneous populations of colorectal cancer patients and patient numbers, among other factors makes the direct comparison of data in the literature difficult. In addition, the number of studies examining the impact of IGF-IR expression on the survival of colorectal cancer patients is limited. Like Hakam and colleagues (18) we did not find any significant association between the expression of IGF-IR and overall survival in colorectal cancer patients (Fig. 2A). In addition, we found no significant correlation between IGF-IR expression and overall survival using different cut-off values of $>1 \%$ and $>50 \%$ expression (data not shown). While the expression of the IGF-IR did not have prognostic significance in this study, the frequent expression of IGF-IR among this series of patients makes it a suitable target for the new generation of receptorspecific drugs $(8-10,15)$. In this study, $60 \%$ of Dukes' C colorectal cancer cases expressed the membranous IGF-IR in $>10 \%$ of tumour cells (Table II). The membranous IGF-IR in such patients would form a good target for therapy with antibodies to the external domain of the receptor (15).

A number of studies have shown that the IGF-IR is able to crosstalk with other receptor systems to enhance the malignant behaviour of tumours. For example, IGF-IR activation has been found to up-regulate the expression of the EGFR ligand $\mathrm{TGF} \alpha$ and result in EGFR activation and re-entry into the cell cycle (13). The expression of IGF-IR has been associated with resistance to anti-EGFR and anti-HER-2 therapies in several experimental systems, and co-targeting the IGF-IR with the EGFR or HER-2 has been shown to reduce the malignant behaviour of tumour cells $(7,14)$. More recently, when combined with anti-EGFR mAb 225 or the chemotherapeutic agent vinorelbine, a humanized anti-IGF-IR antibody has been shown to inhibit more efficiently the growth of the human breast cancer cell line MCF-7 and nonsmall lung cancer cell line A549 in vivo (15). When the 87 Dukes' C colorectal cancer cases were examined for EGFR and HER-2 expression, we found that 83 and $89 \%$ of the cases were positive, respectively (Table II). In addition, coexpression of the three receptors was present in $75 \%$ of the cases. Interestingly, in a recent study by Singer and colleagues (21) IGF-IR, EGFR and HER-2 was detected in only 3\% (2/68 patients), 39\% (27/69 patients) and 4\% (3/68 patients) of a series of 75 colorectal cancer patients, respectively. However, the lower levels of receptors detected in that study may be attributable to the use of tissue microarray, which analyses a smaller region of the heterogeneous tumour biopsy. In addition, there was no investigation on the association between receptor expression and overall survival in that study. In our present study, we found no significant association between the expression of EGFR, HER-2, or receptor coexpression and clinicopathological parameters or with overall survival (Table I and Fig. 2). We have reported recently that cytoplasmic expression of EGFR and the type-III deletion mutant EGFR (EGFRvIII) is associated with improved overall survival in Dukes' C colorectal cancer patients receiving radiotherapy (28). Herein, the expression of EGFR and its coexpression with HER-2, or HER-2 and IGF-IR was also associated with improved overall survival in patients receiving radiotherapy (data not shown).

In the past seven years, several growth factor receptorspecific products, including the anti-HER-2 antibody trastuzumab, the anti-EGFR antibody cetuximab, anti-VEGF antibody avastin, and tyrosine kinase inhibitors gefitinib and erlotinib, have been approved for the treatment of cancer patients $(26,27)$. However, the results of clinical trials with the EGFR inhibitors have only resulted in a response of a short duration in a small subpopulation of patients, and there has been no clear correlation between EGFR levels and response to the EGFR inhibitors $(26,27,29,30)$. In addition, since the expression of IGF-IR has been associated with resistance to anti-EGFR and anti-HER-2 therapies in the experimental setting (12-15) and our results herein indicate that coexpression of the IGF-IR, EGFR and HER-2 is common in patients with Dukes' C colorectal cancer, further investigation on the therapeutic benefit of co-targeting such receptors in colorectal cancer patients is warranted.

\section{Acknowledgements}

We would like to thank Guildford Undetected Tumour Screening (GUTS) charity in the United Kingdom for funding this project.

\section{References}

1. Jemal A, Murray T, Ward E, Samuels A, Tiwari RC, Ghafoor A, Feuer EJ and Thun MJ: Cancer statistics 2005. CA Cancer J Clin 55: 10-30, 2005.

2. Markowitz SD, Dawson DM, Willis J and Willson JK: Focus on colon cancer. Cancer Cell 1: 233-236, 2002.

3. Baserga R: The IGF-I receptor: from rags to riches. Eur J Cancer 40: 2013-2015, 2004 
4. LeRoith D and Roberts CT Jr: The insulin-like growth factor system and cancer. Cancer Lett 195: 127-137, 2003.

5. Reinmuth N, Liu W, Fan F, Jung YD, Ahmad SA, Stoeltzing O, Bucana CD, Radinsky R and Ellis LM: Blockade of insulin-like growth factor receptor function inhibits growth and angiogenesis of colon cancer. Clin Cancer Res 8: 3259-3269, 2002.

6. Perer ES, Madan AK, Shurin A, Zakris E, Romeguera K and Pang YDJ: Insulin-like growth factor I receptor antagonism augments response to chemoradiation therapy in colon cancer cells. J Surg Res 94: 1-5, 2000.

7. Chakravarti A, Loeffler JS and Dyson NJ: Insulin-like growth factor receptor I mediates resistance to anti-epidermal growth factor receptor therapy in primary human glioblastoma cells through continued activation of phoshoinositide 3-kinase signalling. Cancer Res 62: 200-207, 2002.

8. Mitsiades CS, Mitsiades NS, McMullan CJ, Poulaki V, Shringarpure R, Akiyama M, Hideshima T, Chauhan D, Joseph M, Libermann TA, Garcia-Echeverria C, Pearson MA, Hofmann F, Anderson KC, and Kung AL: Inhibition of the insulin-like growth factor receptor-1 tyrosine kinase activity as a therapeutic strategy for multiple myeloma, other hematologic malignancies, and solid tumours. Cancer Cell 5: 221-230, 2004.

9. Hailey J, Maxwell E, Koukouras K, Bishop WR, Pachter JA and Wang Y: Neutralizing anti-insulin-like growth factor receptor 1 antibodies inhibit receptor function and induce receptor degredation in tumour cells. Mol Cancer Ther 1: 1349-1353, 2002.

10. Adams TE, McKern NM and Ward CW: Signalling by the type I insulin-like growth factor receptor: interplay with the epidermal growth factor receptor. Growth Factors 22: 89-95, 2004.

11. Burgaud J-L and Baserga R: Intracellular transactivation of the insulin-like growth factor I receptor by an epidermal growth factor receptor. Exp Cell Res 223: 412-419, 1996.

12. Lu Y, Zi X, Zhao Y, Mascarenhas D and Pollak M: Insulin-like growth factor-I receptor signaling and resistance to Trastuzumab (Herceptin). J Natl Cancer Inst 93: 1852-1857, 2001.

13. Wang D, Patil S, Li W, Humphrey LE, Brattain MG and Howell GM: Activation of the TGF $\alpha$ autocrine loop is downstream of IGF-I receptor activation during mitogenesis in growth factor dependent human colon carcinoma cells. Oncogene 21: 2785-2796, 2002.

14. Camirand A, Lu Y and Pollak M: Co-targeting HER-2/ErbB2 and insulin-like growth factor-I receptors causes synergistic inhibition of growth on HER-2-overexpressing breast cancer cells. Med Sci Monit 8: 521-526, 2002.

15. Goetsch L, Gonzalez A, Leger O, Beck A, Pauwels PJ, Haeuw JF and Corvaia N: A recombinant humanised anti-insulin-like growth factor receptor type I antibody (h7C10) enhances the antitumour activity of vinorelbine and anti-epidermal growth factor receptor therapy against human cancer xenografts. Int $\mathbf{J}$ Cancer 113: 316-328, 2005.

16. Ouban A, Muraca P, Yeatman T and Coppola D: Expression and distribution of insulin-like growth factor-I receptor in human carcinomas. Hum Pathol 34: 803-808, 2003.
17. Zenilman ME and Graham W: Insulin-like growth factor I receptor messenger RNA in the colon is unchanged during neoplasia. Cancer Invest 15: 1-7, 1997.

18. Hakam A, Yeatman TJ, Lu L, Mora L, Marcet G, Nicosia SV, Karl RC and Coppola D: Expression of insulin-like growth factor-I receptor in human colorectal cancer. Hum Pathol 30: 1128-1133, 1999.

19. Weber MM, Fottner C, Liu SB, Jung MC, Engelhardt D and Baretton GB: Overexpression of the insulin-like growth factor I receptor in human colon carcinomas. Cancer 95: 2086-2095, 2002.

20. Peters G, Gongoll S, Langner C, Mengel M, Piso P, Klempnauer J, Ruschoff J, Kreipe H and von Wasielewski R: IGF-1R, IGF-I and IGF-2 expression as potential prognostic and predictive markers in colorectal cancer. Virchows Arch 443: 139-145, 2003.

21. Singer CF, Hudelist G, Lamm W, Mueller R, Czerwenka K and Kubista E: Expression of tyrosine kinases in human malignancies as potential targets for kinase-specific inhibitors. Endocr Relat Cancer 11: 861-869, 2004.

22. Adenis A, Peyrat JP, Hecquet B, Delobelle A, Depadt G, Quandalle P, Bonneterre J and Demaille A: Type-I insulin-like growth factors in human colorectal cancer. Eur J Cancer 31: 50-55, 1995.

23. Essapen S, Thomas H, Green M, De Vries C, Cook MG, Marks C, Topham $\mathrm{C}$ and Modjtahedi $\mathrm{H}$ : The expression and prognostic significance of HER-2 in colorectal cancer and its relationship with clinicopathological parameters. Int J Oncol 24: 241-248, 2004.

24. Modjtahedi H, Moscatello DK, Box G, Green M, Shotton C, Lamb DJ, Reynolds LJ, Wong AJ, Dean C, Thomas H and Eccles S: Targeting of cells expressing wild-type EGFR and type-III mutant EGFR (EGFRvIII) by anti-EGFR MAb ICR62: a two-pronged attack for tumour therapy. Int J Cancer 5: 273-280, 2003.

25. Styles JM,Harrison S, Gusterson BA and Dean CJ: Rat monoclonal antibodies to the external domain of the product of the C-erbB-2 proto-oncogene. Int J Cancer 45: 320-324, 1990.

26. Baselga J and Artega CL: Critical update and emerging trends in epidermal growth factor receptor targeting in cancer. J Clin Oncol 23: 2445-2459, 2005.

27. Modjtahedi H: Molecular therapy of head and neck cancer. Cancer Metastasis Rev 24: 129-146, 2005.

28. Cunningham MP, Essapen, Thomas H, Green M, Lovell DP, Topham C, Marks CG and Helmout Modjtahedi: Coexpression, prognostic significance and predictive value of EGFR, EGFRvIII and phosphorylated EGFR in colorectal cancer. Int J Oncol 27: 317-326, 2005.

29. Cunningham D, Humblet Y, Siena S, Khayat D, Bleiberg H, Santoro A, Bets D, Mueser M, Harstrick A, Verslype C, Chau I and van Cutsem E: Cetuximab monotherapy and cetuximab plus irinotecan in irinotecan-refractory metastatic colorectal cancer. N Engl J Med 351: 337-345, 2004.

30. Giaccone G: HER1/EGFR-targetted agents: predicting the future for patients with unpredictable outcomes to therapy. Ann Oncol 16: 538-548, 2005. 